copyn.. -

Copyright (to be inserted by the publisher)

\title{
The Effect of Holding Pressure on the Shrinkage and Birefringence of Injection Moulded Polypropylene Plates
}

\author{
A. J. Pontes, M. J. Oliveira, A. S. Pouzada \\ Department of Polymer Engineering, University of Minho,Campus de Azurém, 4800-058 \\ Guimarães, Portugal
}

Keywords: Injection moulding, shrinkage, birefringence, polypropylene.

\begin{abstract}
This paper shows the results of shrinkage and birefringence of injection moulded plates. The study was done with two polypropylenes with different MFI. Focus is made on the effect of the holding pressure on the experimental as-moulded shrinkage and birefringence in the flow direction. The mouldings are edge gated flat rectangular plate. The moulding process was continuously monitored with pressure transducers. The results show that the rise of holding pressure determines the decrease of the shrinkage. Also, it was observed that the increase of the pressure applied during the holding phase and the associated flow induce re-orientation of the melt, especially in the case of higher molecular weight PP. Consequently, an increase in the birefringence results.
\end{abstract}

\section{Introduction}

Injection moulding of thermoplastics is suitable to obtain polymeric products with high production rates. Since high dimensional accuracy is more and more required, the analysis of shrinkage becomes a mandatory issue in quality control.

In injection moulding, where the polymer melt is forced to flow through long and narrow spaces and to cool down at fast rates, molecular orientation builds up in the moulded part. This is particularly relevant where the shear stresses and the cooling rates are higher. The thermomechanical conditions experienced by the material during processing will affect the shrinkage of injection moulded products. Also, due to the cooling of the melt occurring at different rates and times, in the case of rigid materials residual stresses may also set up in the mouldings.

Unbalanced molecular orientation or residual stresses cause birefringence in the moulded material. Thus the detection and the measurement of the birefringence is a way to characterize the molecular orientation and the residual stress field in injection mouldings. As, in general, the molecular orientation is dominant over the residual stresses, the birefringence is considered a reliable indirect measurement of the molecular orientation [1].

In this work two polypropylenes with different molecular weights (associated to the corresponding melt flow indices, MFI) were moulded in plates, for studying the influence of the processing parameters on the shrinkage and the molecular orientation. Polypropylene is a semicrystalline polymer very sensitive to the processing conditions. The spherulitic morphology that usually forms under quiescent conditions is highly altered when the crystallization is done under the effect of shear stresses, as it occurs in injection moulding. The change of the rate of cooling or the level of stresses during processing causes modifications on the size and on the type of the developing crystalline textures [2-4]. The influence of the holding pressure on the shrinkage and on the morphology and the birefringence field of the parts are also analyzed.

\section{Experimental}

Materials. Two commercial injection-moulding grades of polypropylene (PP) from Targor, were used. These grades have different melt flow indices. The MFI $\left(230^{\circ} \mathrm{C} / 21.6 \mathrm{~N}\right)$ of the Moplen $\mathrm{HP} 456 \mathrm{H}$ is of $2 \mathrm{~g} / 600 \mathrm{~s}$ and of the Novolen $1100 \mathrm{~N}$ is of $12 \mathrm{~g} / 600 \mathrm{~s}$.

Moulding. The studies were based in injection moulded polypropylene plates $(2 \mathrm{~mm} \times 40 \mathrm{~mm} \times$ $120 \mathrm{~mm}$ ) filled with a parallel flow (Fig. 1). During processing the evolution of pressure was 
recorded. The moulding programme was performed with a cell consisting of a Krauss Maffei KM60/210A injection moulding machine of $600 \mathrm{kN}$ clamp force and a thermal regulator, Klöckner Ferromatic Desma - T10EW403

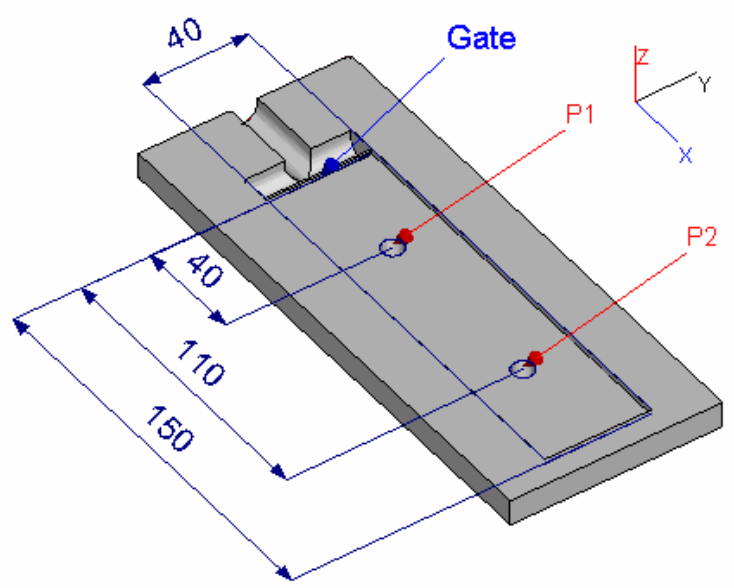

Fig. 1. Cavity dimensions and pressure transducer locations
The melt and mould temperatures were set at $210^{\circ} \mathrm{C}$ and $24^{\circ} \mathrm{C}$ respectively, for both materials. The holding pressure was varied as indicated in Table 1.

Table 1. Processing conditions of the mouldings

\begin{tabular}{cc}
\hline $\begin{array}{l}\text { Sample } \\
\text { identification }\end{array}$ & $\begin{array}{c}\text { Holding Pressure } \\
\text { (MPa) }\end{array}$ \\
\hline HP456H -12 & 12 \\
HP456H -25 & 25 \\
HP456H -40 & 40 \\
1100 N-12 & 12 \\
1100 N-25 & 25 \\
1100 N-40 & 40 \\
\hline
\end{tabular}

Shrinkage measurements. The shrinkage is calculated as $\left(\mathrm{L}_{0}-\mathrm{L}\right) / \mathrm{L}_{0}$ where $\mathrm{L}_{0}$ is the original dimension of the mould, and $\mathrm{L}$ is the dimension of the sample.

The mouldings were measured with a LVDT transducer (precision of $\pm 1 \mu \mathrm{m}$, for the length), a digital calliper (precision $\pm 10 \mu \mathrm{m}$, for the width), and a micrometer (precision $\pm 10 \mu \mathrm{m}$, for the thickness) at a room temperature of $23^{\circ} \mathrm{C}$.

The shrinkage was statistically characterised by average and standard deviation of a set of 5 specimens.

Microscopical analysis. The mouldings, that lend themselves to thin sectioning, were microtomed using a Leitz 1401 apparatus in 15 to $35 \mu \mathrm{m}$-thick sections for birefringence measurement and morphological analysis. For this purpose, an Olympus $\mathrm{BH} 2$ polarized light microscope set with a Berek compensator was used.

\section{Results and discussion}

The microscopical images of the cross-sections of the mouldings showed that typical skin-core morphology is formed. The Figure 2 exemplifies this type of texture for both materials.

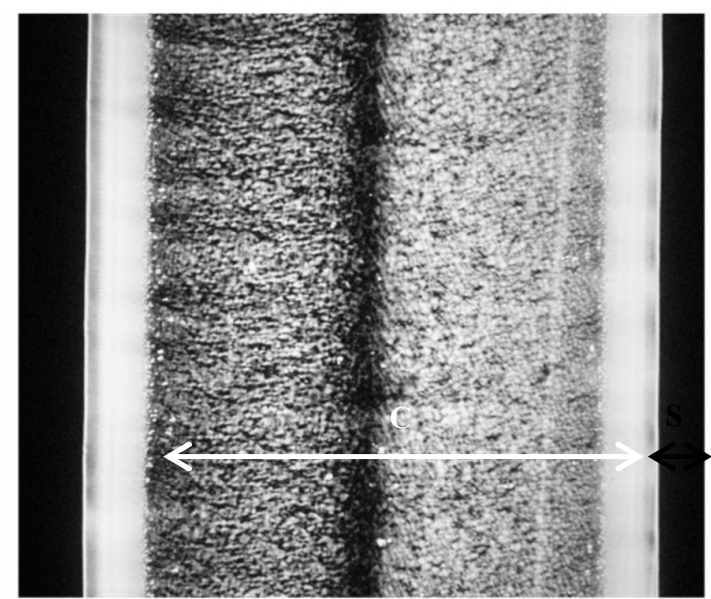

a) $1100 \mathrm{~N}-25$
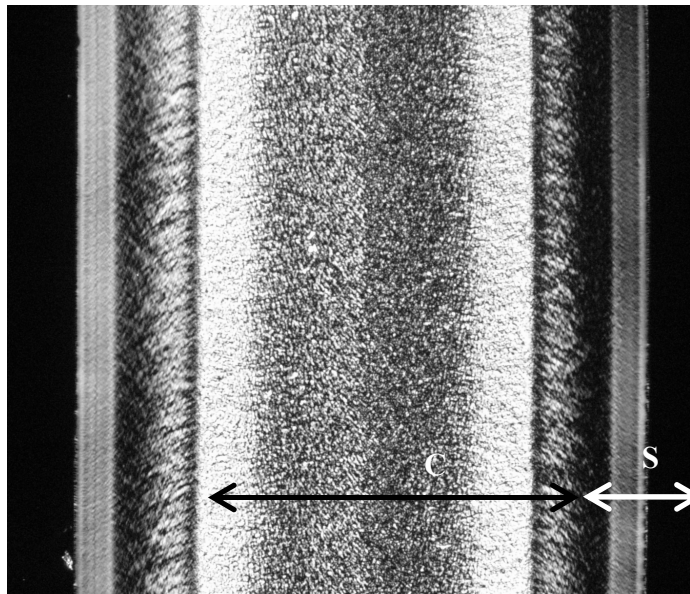

b) $\mathrm{HP} 456 \mathrm{H}-25$

Fig. 2. Longitudinal cross-sections microtomed in the middle of the flow path. $\mathrm{S}-$ skin; $\mathrm{C}-\mathrm{Core}$. 


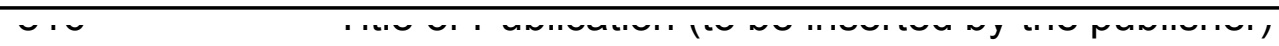

The texture and birefringence vary across the width, the core being spherulitic and the skin layers non-spherulitic. The molecular orientation is higher at the skin layers, which solidified first during the filling of the moulding. The overall orientation of the PP mouldings can be related to the skin-core ratio and thermo-mechanical indices that reflect the processing conditions and material characteristics [4].

The molecular weight of the polymer influences the morphology and its dependence on the holding pressure. When the molecular weight is lower (or the MFI is higher) the skin is narrower and the skin birefringence is lower than when the material has a higher molecular weight, as it can be seen in the Figure 2 and Table 2. In the case of the Moplen HP456H (MFI 2) plates the variation of the holding pressure did not cause apparent modifications in the skin width or in the level of birefringence (as shown in figure 3 and Table 2). However the holding pressure appears to influence the level of orientation at the core. The mouldings made with the lowest holding pressure (figure 3a) show a core with uniform brightness and no signs of molecular orientation. Differently, the mouldings that withstood a higher holding pressure (figure 3-b and 3-c) present a spherulitic core with two bright layers adjacent to the skin (as indicated in the pictures). The thickness of these layers increase with the holding pressure. Due to the solidification of the skin occurring before the pressurization stage of the cycle, the holding pressure does not affect this layer. In the core, which solidified later and under the action of the holding pressure, the material suffered re-orientation caused by the compensating flow.

Table 2. Birefringence of the plates measured in the flow direction

\begin{tabular}{cc}
\hline Sample identification & Max. Birref. $\times 10^{3}$ \\
\hline HP456H -12 & $28,5 \pm 0,5$ \\
HP456H -25 & $26,6 \pm 0,5$ \\
HP456H -40 & $30,5 \pm 0,5$ \\
$1100 \mathrm{~N}-12$ & $12,6 \pm 0,5$ \\
$1100 \mathrm{~N}-25$ & $11,6 \pm 0,5$ \\
$1100 \mathrm{~N}-40$ & $10,6 \pm 0,5$ \\
\hline
\end{tabular}

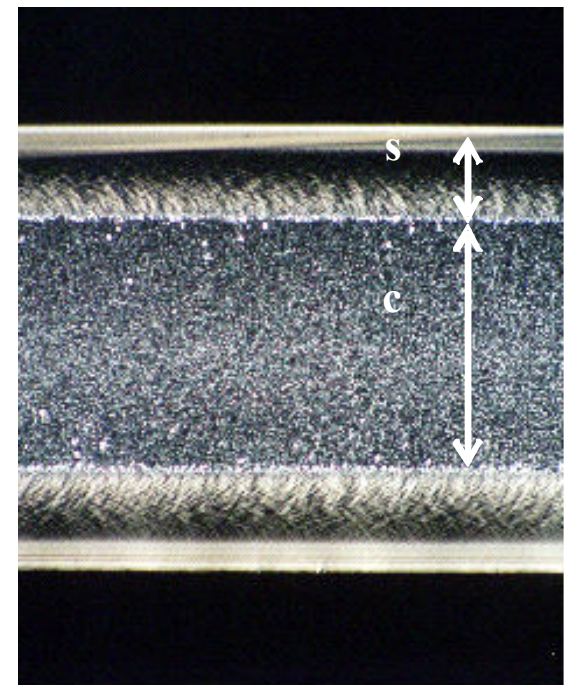

a) $\mathrm{HP} 456 \mathrm{H}-12$

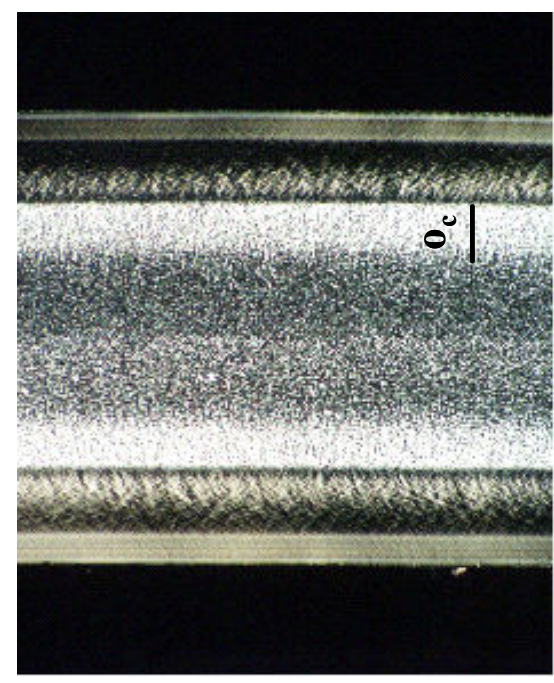

b) $\mathrm{HP} 456 \mathrm{H}-25$

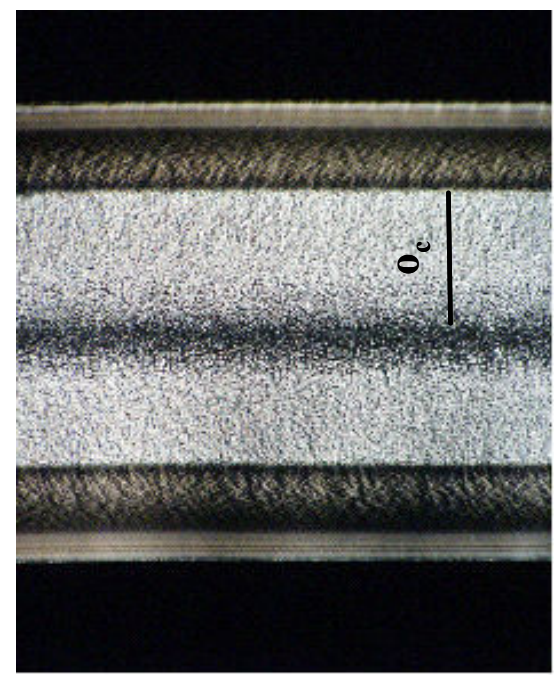

c) $\mathrm{HP} 456 \mathrm{H}-40$

Fig. 3. Longitudinal cross-sections of Moplen HP456H plates moulded with different holding pressures. S skin; C - Core; Oc - oriented core.

The shrinkage results, which were plotted in figures 4 and 5 for Moplen HP456H and Novolen $1100 \mathrm{~N}$, respectively, show that the increase of the holding pressure causes the shrinkage to decrease. 

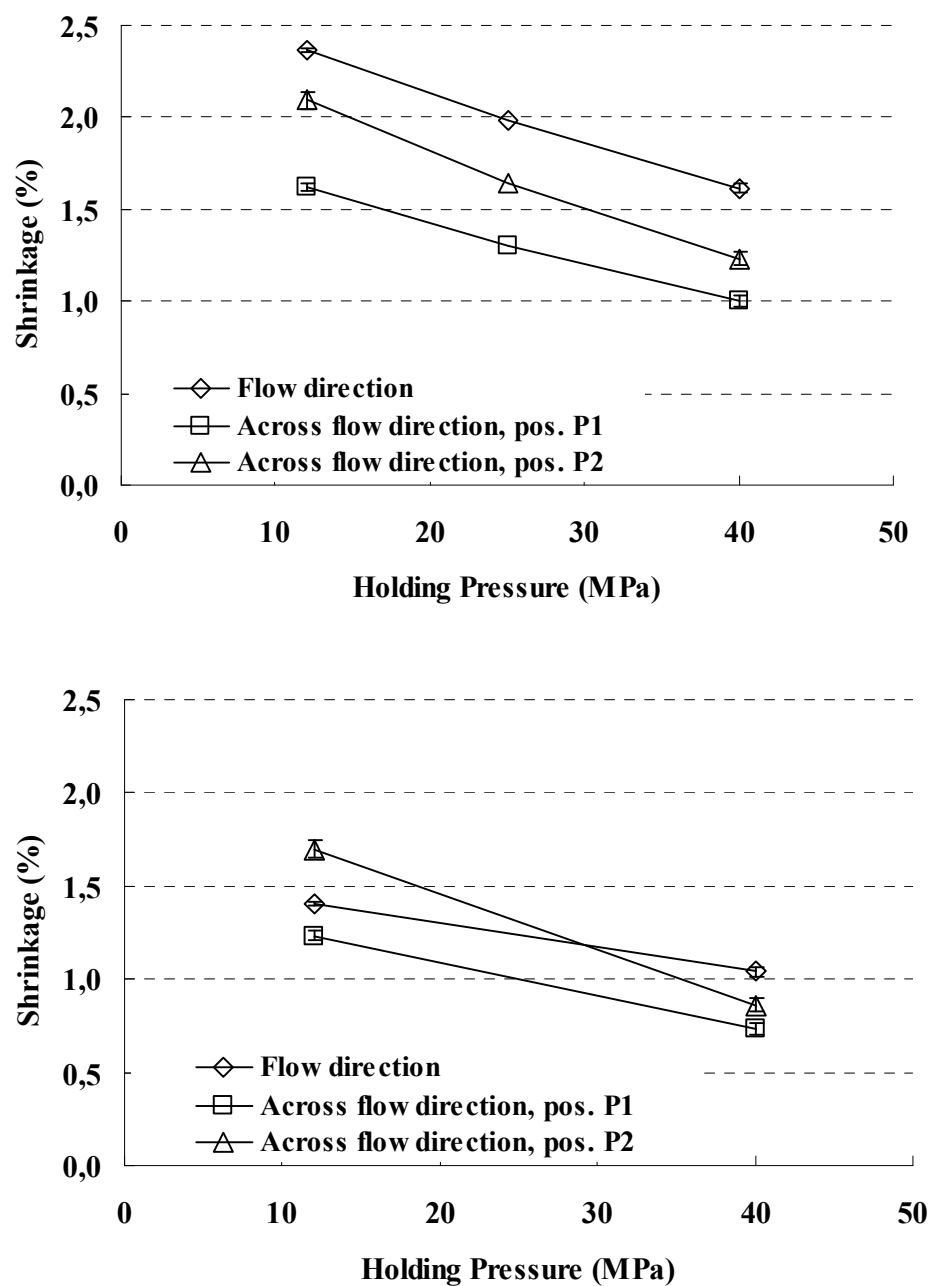

Fig. 4. As-moulded shrinkage of Moplen HP456H plates in the flow and across flow directions

Fig. 5. As-moulded shrinkage of Novolen $1100 \mathrm{~N}$ plates in the flow and across flow directions.

The material with a lower molecular weight (Novolen $1100 \mathrm{~N}$ ) undergoes an overall shrinkage lower that the highest molecular weight material (Moplen HP456H). This is a result of the viscosity of the former being lower and the corresponding flowability being better, enabling the holding pressure induced flow compensating the shrinkage of the moulded material.

\section{Conclusions}

The holding pressure and the associated flow induced re-orientation of the melt in the mould and consequently cause the birefringence to increase. For both materials, this effect is more evident in the core of the moulding than at near the surface.

The shrinkage data from the two materials plates, also moulded with different holding pressures showed that the shrinkage decreases when the holding pressure increases. Materials with higher MFI or lower molecular weight produce mouldings with smaller shrinkage than materials of higher molecular weight.

\section{References}

[1] R. Friedl Wimberger: Prog. Polym. Sci., Vol. 20 (1995), p.369.

[2] J. Karger-Kocsis: Polypropylene: Structure, Blends and Composites, (ed.), Chapman and Hall, London (1995).

[3] A.M. Cunha: A Study on the Mechanical Behaviour of Injection Moulded Polypropylene Parts, Universidade do Minho, Braga, 1991. PhD Thesis.

[4] J.C. Viana: Mechanical Characterisation of Injection Moulded Plates, Universidade do Minho, Braga, 1999. PhD Thesis. 